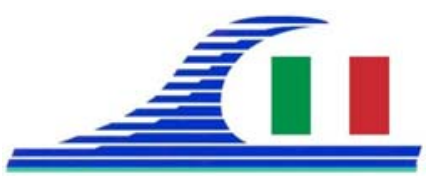

Conférence Méditerranéenne Côtière et Maritime EDITION 3, FERRARA, ITALIA (2015)

Coastal and Maritime Mediterranean Conference

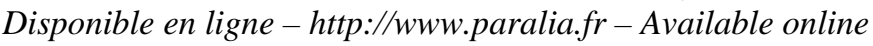

\title{
Efficient inspection work of hydraulic structures including on-site physical testing
}

\author{
Bärbel KOPPE $^{1}$, Marc GUTERMANN ${ }^{2}$
}

1. City University of Applied Sciences Bremen, Institute for Hydraulic and Coastal Engineering (IWA), Bremen, Germany. baerbel.koppe@hs-bremen.de

2. City University of Applied Sciences Bremen, Institute for Experimental Statics (IFES), Bremen, Germany.marc.gutermann@hs-bremen.de

\begin{abstract}
:
Precise and efficient inspection work is crucial for long-living, utilizable, and safe hydraulic structures. The inspection of waterway constructions in Germany is subject to a cyclical regime of inspections. In case degradations and damages occur, but structural reanalysis is not possible due to missing construction documents and / or unclear load paths, on-site experimental testing may be the appropriate way to get an insight in the available load capacity of the structure. The paper gives an overview on the existing inspection regulations of the German Federal Waterways and Shipping Administration as well as an insight in practical inspection works including on-site physical testing.
\end{abstract}

Keywords: Coastal engineering, Maritime structures, Inspection works, Damage classes, On-site physical testing

\section{Introduction}

The age structure of constructions in waterways and harbors is getting more and more unfavorable. Nearly 30\% of the locks in German waterways are older than 100 years and have exceeded their expected lifetime (WSV, 2007). Similar conditions exist on waterways as well as in inland harbors and partly in seaports. To ensure also in future a sufficient quality of waterways and harbors as well as a safe utilization of riverbanks, shorelines and infrastructure a cost-efficient maintenance management system is necessary to guarantee an efficient prioritization of repair and replacement works and an effective use of limited resources.

\section{Inspection of hydraulic structures}

An important base for maintenance management systems is a precise and efficient inspection of the structures based on hydraulic, structural and material knowledge. The inspection of waterway constructions is subject to a cyclical regime of inspections (BAW, 2010):

- annual inspections by qualified persons to check the overall status of the building,

- every six years monitoring of the building by qualified engineers including the assessment of the structural bearing capacity and the serviceability of the building, 
Côtes méditerranéennes menacées :

Risques et défis dans le contexte du changement climatique

- every six years manual examination of the building by qualified engineers including drainage of the structure or diving operations.

The inspection cycle ensures principal examinations by engineers every three years by alternation of monitoring and manual examination.

According to the guidelines of the German Federal Waterways and Research Institute five damage classes can be distinguished (BAW, 2011):

- Damage Class 0: no damage,

- Damage Class 1: damage not influencing the functional soundness and/ or structural stability today and probably also not in future,

- Damage Class 2: damage not or only slightly influencing the functional soundness and/ or structural stability today, but will probably do so in a later stage (further development of damage),

- Damage Class 3: damage influencing the functional soundness and/ or structural stability today, but both, functional soundness and structural stability are still provided; it must be checked if a further monitoring in the given inspection cycle is sufficient or if a shortening of the interval is necessary,

- Damage Class 4: functional soundness and/ or structural stability is not given any more; the damage represents a danger for people and/ or prevents the use of the structure; repair or replacement is necessary.

The damage development according to the defined damage classes is illustrated in Figure 1. Without any repairs and/ or replacement the damages classified in damage class 2 will worsen reaching damage classes 3 and 4 with time. In Figure 2 examples of damage class 2 and 4 are shown. The hatch cover is leaking resulting in corrosion of the steel cover plate. No reinforcement corrosion and concrete spalling is evident, but can be assumed to occur in future. The right hand side illustrates an example of damage class 4 , sort of later stage of the left hand side example.

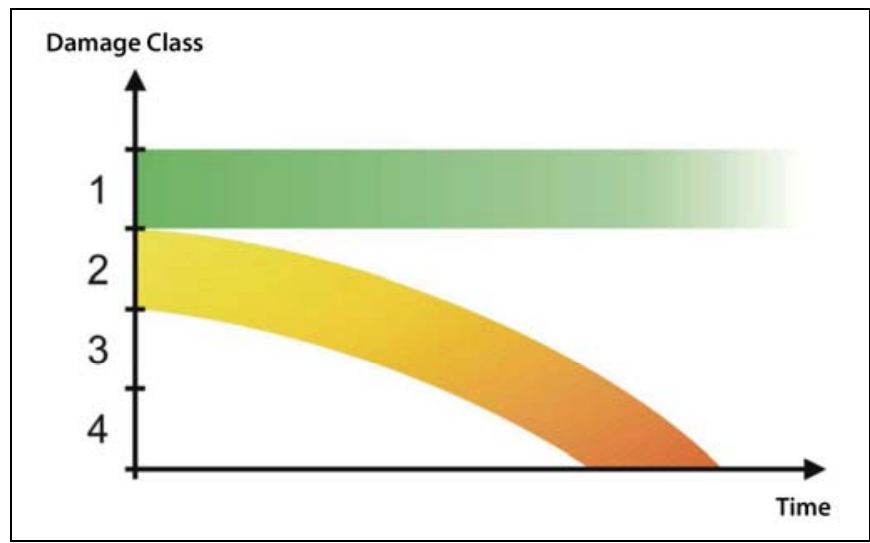

Figure 1. Damage classes versus time (according to BAW, 2011). 

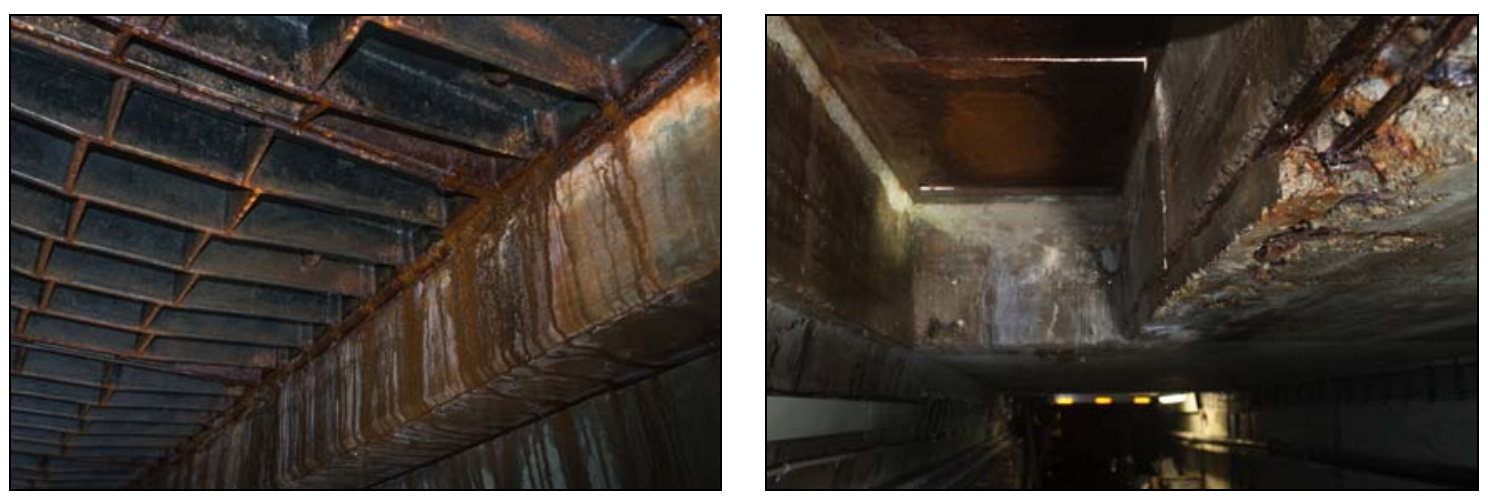

Figure 2. Leaky hatch cover - left damage class 2 - water seepage and corrosion at the steel cover; right damage class 4 - reinforcement corrosion with reduction of cross section and concrete spalling.

The assessment of functional soundness and structural stability is based on the review of planning and construction documents, on-site visual inspection, on-site and laboratory material testing as well as hydraulic and structural calculations. Often, an assessment of the structural condition is difficult as inventory documents are missing, the load path is unclear and damages are so severe that the possibility of a sudden failure of the structure cannot be denied by theoretical calculations. Therefore, experiments can be the appropriate alternative to make a reliable statement on the available load capacity. By experiments, load restrictions or even a closure of the structure may be prevented and a proper and sound planning of repair or replacement works may be possible.

\section{Experimental safety assessment}

Load tests assess the effective load bearing behavior of structures by measuring the effects during external loading on the structure (e.g. deformations). Experimental safety evaluation without causing any damage is tied to two important technical prerequisites:

- the application of test loads has to be undertaken in a way that sudden failure of the structure is avoided even in case of unexpected damage,

- during test loading the reactions of the structure have to be monitored continuously and evaluated in real time (e.g. deformations and micro crack formation).

Thus, information above the service load level can be assessed experimentally up to an unknown load limit, which marks the beginning of irreversible damage (Figure 3). Very often additional resistance reserves are revealed, especially in case of inhomogeneous materials like concrete or masonry. This is often based on several effects:

- the characteristic properties of non-metallic materials vary in a wide range and the assumptions for calculation often underestimate the real value significantly,

- real boundary conditions differ from the mathematical model,

- the structure is able to change the load flow, thus stronger structural parts may help weaker parts, e.g. caused by faults. 
Côtes méditerranéennes menacées :

Risques et défis dans le contexte du changement climatique

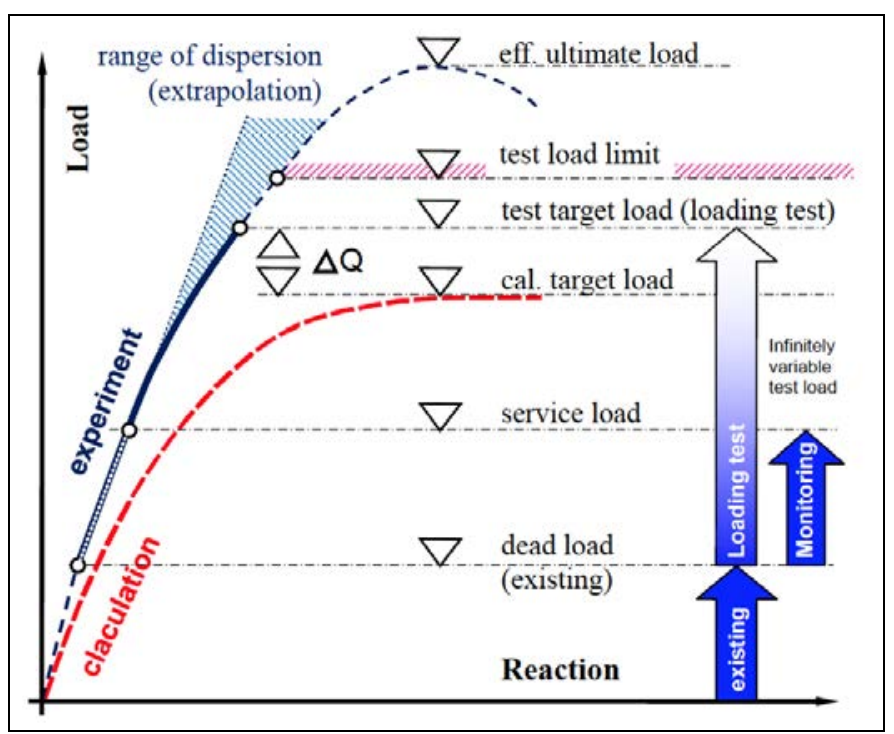

Figure 3. Theoretical and experimental load-reaction-curve of a structure (GUTERMANN, SCHRÖDER, 2013).

\section{Example of an experimental safety assessment - anchored sheet pile wall in Bremen}

The quay of the former shipyard AG WESER in Bremen, northern Germany, consists of a two level re-anchored sheet pile wall to restrain an altitude difference of $20 \mathrm{~m}$. The wall showed local horizontal deformation up to multi-decimeters. By using a mobile loading set-up (Figure 4) broken anchors as well as still existing anchor forces could be identified, providing a basis for the planning and execution of reinforcements. Today, one of the main shopping malls of the city of Bremen, the Waterfront Shopping Mall, is located in this area.

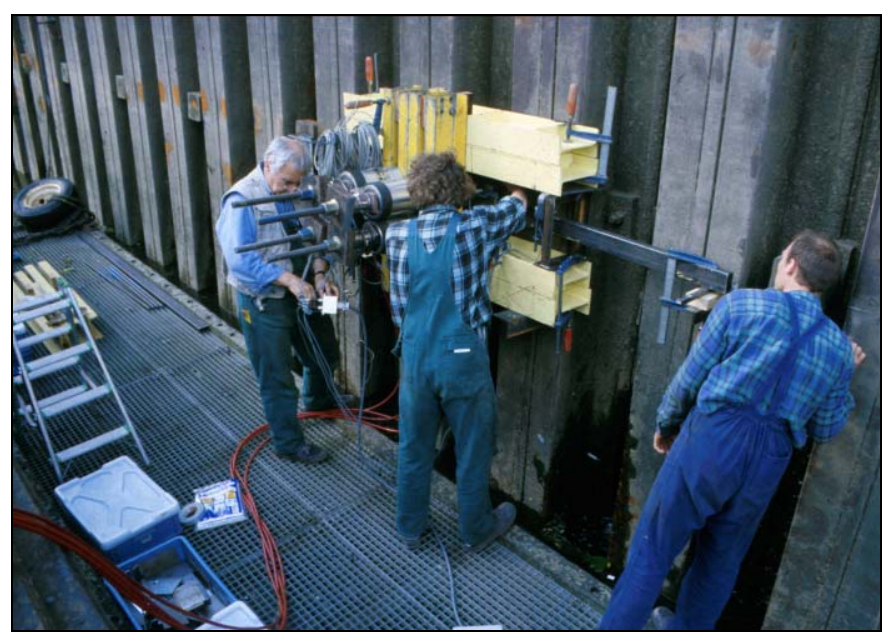

Figure 4. Load tests of anchored sheet pile wall. 
Mediterranean coasts at threat:

Hazards and challenges in the context of climate variability

\section{Conclusions}

For long-living, utilizable, and safe hydraulic structures periodical precise and efficient inspection works are crucial. Difficulties may arise if degradations and damages occur, but structural reanalysis is not possible due to missing construction documents and / or unclear load paths. Then, experiments can be an appropriate alternative to make a reliable statement on the available load capacity. Proper experimental testing is based on controlled load supply and continuous monitoring and assessment of the reaction of the structure.

Experiments can deliver information about the real structural behaviour under different boundary conditions. Often, experimental investigations produce more favourable results than static calculations. Therefore, proper on-site physical testing can deliver reliable results on available load capacities and load restrictions or even closure of structures can often be prevented without any restrictions in safety.

\section{References}

BAW (2010). BAW Information Sheet Structural Inspections (BAW Merkblatt Bauwerksinspektion - MBI). German Federal Waterways and Research Institute (Bundesanstalt für Wasserbau - BAW).

BAW (2011). Information Sheet Damage Classification at Waterway Constructions (Merkblatt Schadensklassifizierung an Verkehrswasserbauwerken - MSV). German Federal Waterways and Research Institute (Bundesanstalt für Wasserbau - BAW).

GUTERMANN M., SCHRÖDER C. (2013). Loading Vehicle BELFA. Development and experience gained in 10 years of practice. Proceedings CSHM-5 Workshop on Civil Structural Health Monitoring, Ube/Japan.

WSV (2007). Locks and Ship Lifts at Federal Waterways (Abstiegsbauwerke an Bundeswasserstrassen). Data base of the Federal Waterways and Shipping Administration of Germany (Wasser- und Schifffahrtsverwaltung - WSV), June 1st 2007. 
Côtes méditerranéennes menacées :

Risques et défis dans le contexte du changement climatique 